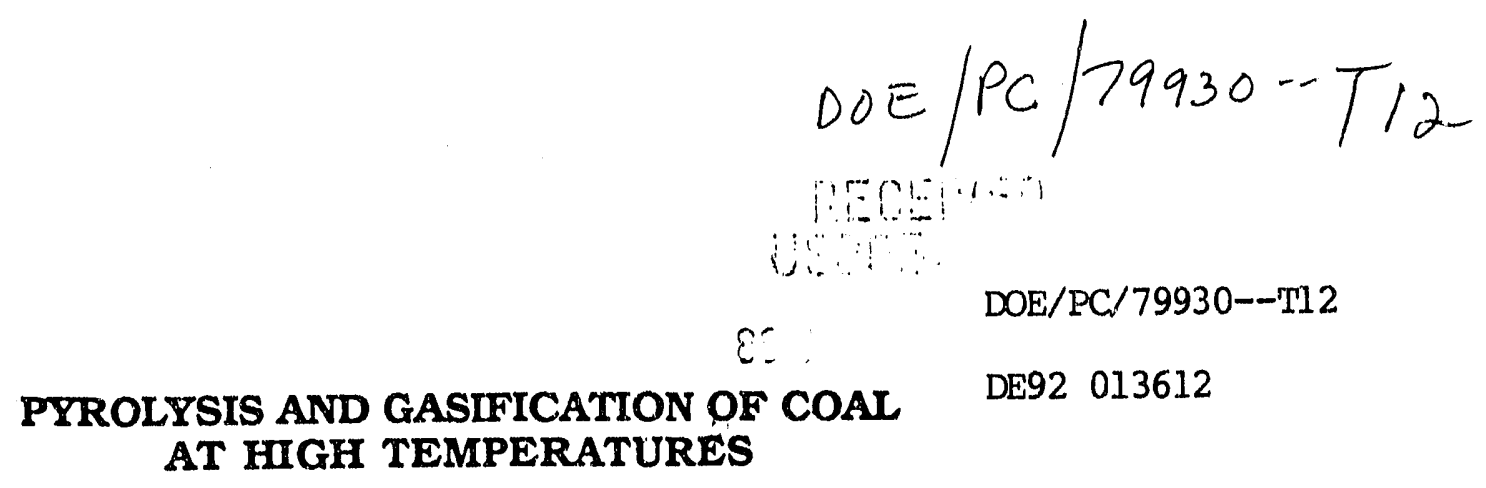

Grant Number DE-FG22-87PC79930

QUARTERLY PROGRESS REPORT

(Quarter \#7: $3 / 15 / 1989$ to $6 / 15 / 89$ )

PRINCIPAL INVESTIGATOR: Prof. Kyriacos Zygourakis

Department of Chemical Engineering Rice University

Houston, Texas 77251-1892

Tel. (713) 527-8101 Ext. 3509.

PROJECT MANAGER:

Dr. James R. Longanbach

Morgantown Energy Technology Center

PO Box 880

Collins Ferry Road

Morgantown, West Virginia 26505.

GRANT PERIOD:

$9 / 15 / 1987$ to $9 / 14 / 1990$

US/DOE Patent Clearance is not required prior to the publication of this document 


\section{SHORT DESCRIPTION OF TASKS}

\section{(A) Effects of Pyrolysis Conditions on Macropore Structure}

Coals of different ranks will be pyrolyzed in a microscope hot-stage reactor using inert and reacting atmospheres. The macropore structure of theproduced chars will be characterized using video microscopy and digital image processing techniques to obtain pore size distributions. Comparative studies will quantify the effect of pyrolysis conditions (heating rates, final heat treatment temperatures, particle size and inert or reacting atmosphere) on the pore structure of the devolatilized chars.

\section{(B) Gasification Under Strong Intraparticle Diffusional Limitations}

The devolatilized chars will be gasified in the regime of strong intraparticle diffusional limitations using $\mathrm{O}_{2} / \mathrm{N}_{2}$ and $\mathrm{O}_{2} / \mathrm{H}_{2} \mathrm{O} / \mathrm{N}_{2}$ mixtures. Constant temperature and programmed-temperature experiments in a TGA will be used for these studies. Additional gasification experiments performed in the hot-stage reactor will be videotaped and selected images will be analyzed to obtain quantitative data on particle shrinkage and fragmentation.

\section{(C) Mathematical Modeling and Model Valldation}

Discrete mathematical models will be developed and validated using the experimental gasification data. Structural properties of the unreacted chars will be used to generate computational grids simulating the pore structure of the solid. Simulations will then provide the evolution of observed reaction rates with conversion. The size distribution of particle fragments obtained as the reaction front moves through the particle will also be obtained. Proper statistical averaging of the results from these simulations will yleld the expected behavior for each char. Comparisons of experimental data and theoretical predictions will Identify the fundamental phenomena that must be included in a mathematical description of the process, thus leading to the development of accurate models for the gasification of coal particles. 


\section{SUMMARY}

Our studies in the past quarter focused on the experimental determination of char reactivity at high temperatures where intraparticle diffusional limitations become very important. Two experimental procedures were carefully evaluated and the gasification behavior of an illinols \#6 char prepared from a demineralized coal was studied in detall. Demineralization of the coal simplified the analysis of data by eliminating the possibility of significant catalytic effects As expected, diffusional limitations significantly affected the reactivity patterns. As the reaction temperatures increased, the maxima of the reactivity vs. conversion curves were shifted towards smaller converstons and the curves exhibited a distinct inflection point. The experimental observations agreed with trends predicted by our theoretical models. We are currently planning to extend the reactivity studles to even higher temperatures, to use larger char particles and to carry out a systematic comparison of experimental data to model predictions.

\section{TASK B: GASITICATION IN THE REGIME OF DIFFUSIONAL LIMTTATIONS}

The thermogravimetric reactor was used for the reaction rate measurements of an Illinois $\# 6$ char. The sample was prepared from a demineralized coal sample in the fluidized bed reactor (approximately $0.1 \mathrm{C} / \mathrm{s}$ heating rate). The size of the particles was in the 50-60 mesh range

We initially planned to use the "constant temperature" experimental procedure, where the sample is heated in a nitrogen atmosphere first to $150 \mathrm{C}$ (and kept there for 20 minutes to remove the motsture) and then ramped to the final reaction temperature at a rate of 300 $\mathrm{C} / \mathrm{min}$. When the system stabilizes at the final temperature, oxygen is introduced to the reactor and the reaction is allowed to proceed to $97 \%$ conversion (or until the weight does not. change within a $60 \mathrm{sec}$ period). The temperature is then ralsed again to quickly burn the remaining carbon in order to determine the amount of ash presen in the sample . 
One of the problems with this procedure, is that the concentration of oxygen in the reactor does not reach its final value instantly. This is not important at low temperatures $(450-500 \mathrm{C})$ where the reaction rate is slow and the conversion achieved in 1 or 2 minutes is less than $1 \%$ (at $500 \mathrm{C}$ and $10 \% \mathrm{O}_{2}$, for example, the conversion reaches $1 \%$ after $2 \mathrm{~min}$ ). At higher temperatures, however, significant conversions are observed during the initial transient complicating the analysis and interpretation of the experimental data.

For these reasons, we carefully evaluated the alternative "constant reactant concentration" procedure where the concentration of oxygen is set to the destred value at low temperatures and the sample is then heated as quickly as possible to the final reaction temperature. The heating rates employed for these experiments varied from $600 \mathrm{C} / \mathrm{min}$ to 1500 $\mathrm{C} / \mathrm{min}$ so as to bring the sample to the final temperature within $30 \mathrm{sec}$. The flow conditions and the $\mathrm{O}_{2}$ composition were set at the temperature of $200 \mathrm{C}$. Table 1 presents the conversions achieved during the heating ramp for various final temperatures and oxygen concentrations. Even though this constant concentration procedure worked well for temperatures up to about $700 \mathrm{C}$ and oxygen concentrations up to $10 \%$, substantial conversions were observed for higher final temperatures and reactant concentrations.

The furnace temperature control program was improved and worked well both during the heatup and the steady state periods. Temperature deviations from the setpoint did not exceed the value of $0.25 \mathrm{C}$ (which equals the resolution of the A/D board) during the steady state (see Figure 1). Larger deviations were observed during the heat ramp period (especially when going around the corners of the heating program). The largest deviations did not exceed $10 \mathrm{C}$, lasted lesis than 2 seconds and were only observed for the highest heating rates used $(>1200 \mathrm{C} / \mathrm{min})$. After these transients, the temperature settled at the steady state value in less than 5 secs with an average deviation of $3 \mathrm{C}$. However, based on the activation energy value of $30 \mathrm{kcal} / \mathrm{mole}$ (as mentioned later), the reaction rate constant at $700 \mathrm{C}$ changes by $1.5 \%$ for every degree (C). Thus, temperature deviations of $3 \mathrm{C}$ lead to reaction rate variations of about $4.5 \%$. 


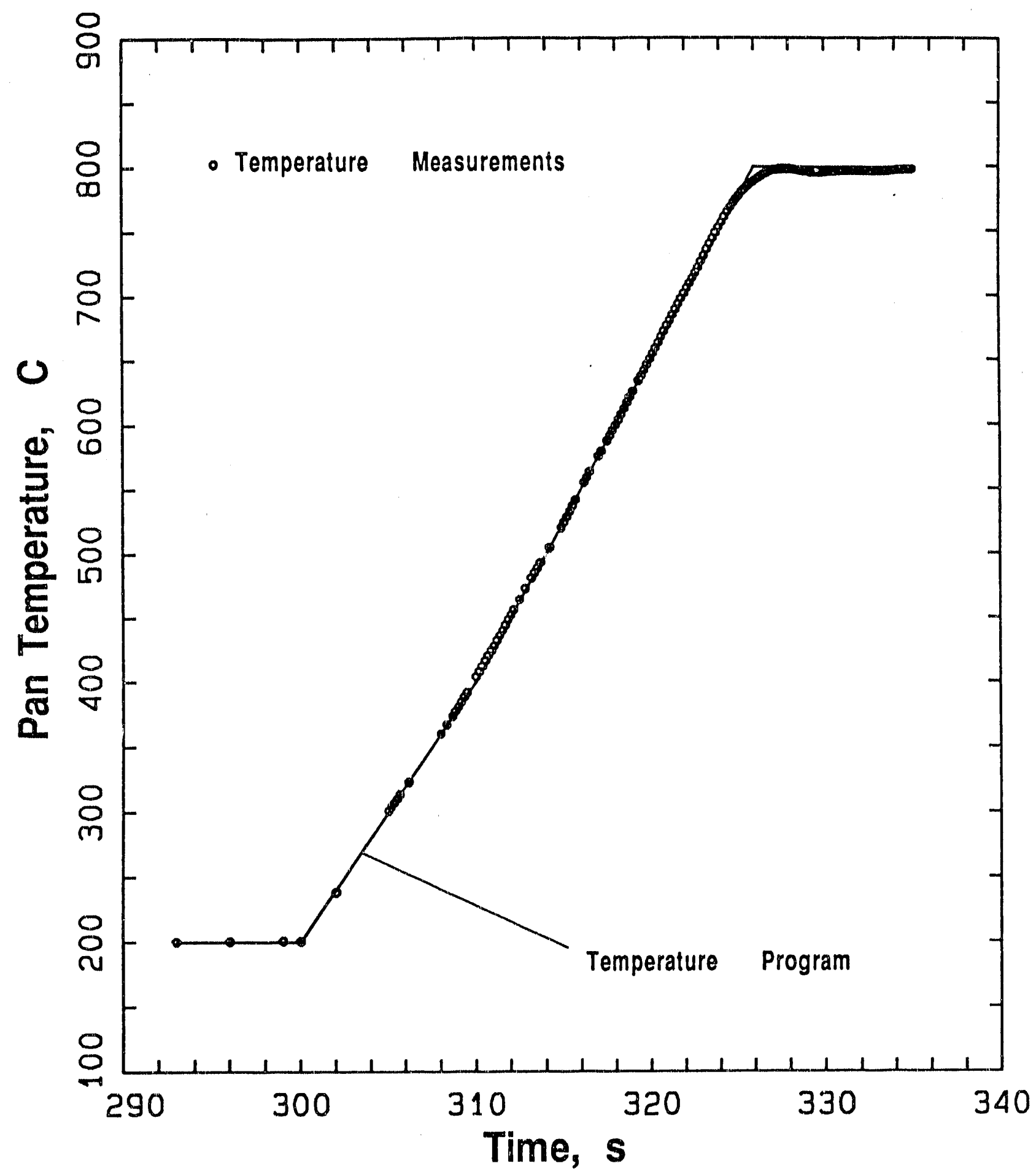

Figure 1: Comparison of temperature program (setpoint:solid line) and measured pan temperatures (data: points) for a typical constant concentration gasification run 
TABIE 1

Conversions $(\%)$ achleved during the heat ramp.

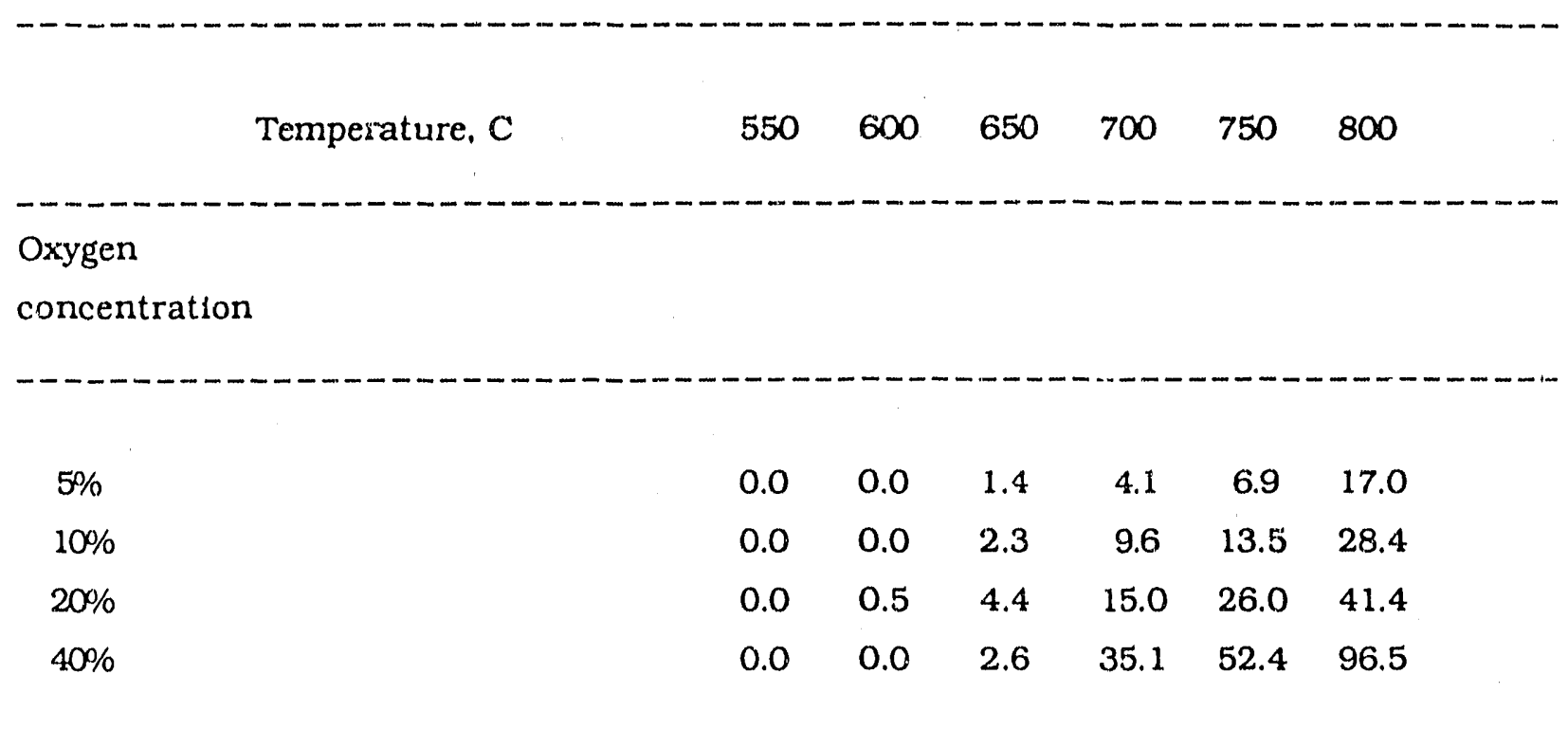

The initial version of the temperature control program did not respond well when the reaction was fast during the ramp and the heat released by the coal combustion was significant enough to create a temperature overshoot To solve this problem, we flrst tried using smaller char samples (in the range of $0.5 \mathrm{mg}$ instead of $2-3 \mathrm{mg}$ as before). However, this was not enough for temperatures of $700 \mathrm{C}$ and higher. A substantial improvement in the controller was achieved by incorporating into the temperature control program a model to monitor th reaction rate and predict the heat release. The reaction rate during the ramp was monitor:d via the the weight change and the released heat was estimated using an empirical constant to relate it with the heat of the furnace and the heat capacity of the pan. This heat was then subtracted from the heat input calculated by the controller. The performance was enhanced significantly and in this way experiments were performed without significant overshoot The controller that did not employ this compensation lead to overshoots higher then $10 \mathrm{C}$. 
Another problem encountered involved estimating the initial weight of the sample. When the sample is heated, the pan deflection changes creating a different offset in the weight measurements. This offset changes by $0.020 \mathrm{mg}$ when the sample is heated from $200 \mathrm{C}$ to $600 \mathrm{C}$. Such changes are not important when using samples larger than $2 \mathrm{mg}$. Since we use small samples here, the initial weight measurement is taken at a temperature of $460-470 \mathrm{C}$. The change of the offset from 470 to 600 or $700 \mathrm{C}$ is not as significant (or it is at least lower). Furthermore, the reaction is starting at this temperature so we are not ignoring any weight change due to reaction. We later followed a more rigorous approach involving calibration experiments with an empty pan and the creation of a master curve that gives the offset change as a function of temperature. We found that this curve depends on the gas composition as well as the heating rate.

\section{DISCUSSION OF RESULTS:}

The range of temperatures used for the combustion experiments was 450-800 C. and oxygen concantrations ranged from $5 \%$ to $40 \%$. Table 2 summarizes some of the reactivity data. However, the most important phenomenon here is the temporal evolution of the active surface area during the course of the reaction and, consequently, the evolution of the reactivity vs. conversion rotterns.

The mist commonly used reactivity measure is the rate $R_{0}$ defined by

$$
R_{0}=\frac{1}{m_{0}} \frac{d m}{d t}
$$

where $m$ is the remaining mass of char and $m_{0}$ is the initial amount of unreacted char. The reaction rate can aiso be computed with respect to the remaining mass of char $\mathrm{m}$

$$
\mathrm{R}_{\mathrm{m}}=\frac{1}{\mathrm{~m}} \frac{\mathrm{dm}}{\mathrm{dt}}
$$

This report was prepared as an account of work sponsored by an agency of the United States Government. Neither the United States Government nor any agency thereof, nor any of their employees, makes any warranty, express or implied, or assumes any legal liability or responsibility for the accuracy, completeness, or usefulness of any information, apparatus, product, or process disclosed, or represents that its use would not infringe privately owned rights. Reference herein to any specific commercial product, process, or service by trade name, trademark, manufacturer, or otherwise does not necessarily constitute or imply its endorsement, recommendation, or favoring by the United States Government or any agency thereof. The views and opinions of authors expressed herein do not necessarily state or reflect those of the United States Government or any agency thereof. 
TABLE 2

Reaction Rates at Varlous Temperatures and Compositions (in $\min ^{-1}$ )

\begin{tabular}{|c|c|c|c|c|c|}
\hline & & $5 \%$ & $10 \%$ & $20 \%$ & $40 \%$ \\
\hline $\begin{array}{l}T, C \\
450\end{array}$ & $\begin{array}{l}\mathrm{R}_{\mathrm{m}} @ 10 \% \text { conv. } \\
\mathrm{R}_{\mathrm{m}} \otimes 50 \% \text { conv. } \\
\text { Maxdmum } \mathrm{Rm} \\
\text { Maxdmum Ro }\end{array}$ & & $\begin{array}{l}0.0081 \\
0.0141 \\
0.0142 \\
0.0090\end{array}$ & $\begin{array}{l}0.0120 \\
0.0228 \\
0.2280 \\
0.0139\end{array}$ & $\begin{array}{l}0.0131 \\
0.0257 \\
0.0257 \\
0.0159\end{array}$ \\
\hline 475 & $\begin{array}{l}\mathrm{R}_{\mathrm{m}} @ 10 \% \text { conv. } \\
\mathrm{R}_{\mathrm{m}} @ 50 \% \text { conv. } \\
\text { Maxdmum Rm } \\
\text { Maximum Ro }\end{array}$ & $\begin{array}{l}0.0079 \\
0.0132 \\
0.0132 \\
0.0086\end{array}$ & $\begin{array}{l}0.0178 \\
0.0291 \\
0.0296 \\
0.0203\end{array}$ & $\begin{array}{l}0.0225 \\
0.0433 \\
0.0433 \\
0.0275\end{array}$ & $\begin{array}{l}0.0252 \\
0.0503 \\
0.0503 \\
0.0302\end{array}$ \\
\hline 500 & $\begin{array}{l}\mathrm{R}_{\mathrm{m}} @ 10 \% \text { conv. } \\
\mathrm{R}_{\mathrm{m}} @ 50 \% \text { conv. } \\
\text { Maxdmum } \mathrm{Rm} \\
\text { Maxdmum Ro }\end{array}$ & $\begin{array}{l}0.0187 \\
0.0284 \\
0.0294 \\
0.0202\end{array}$ & $\begin{array}{l}0.0291 \\
0.0468 \\
0.0468 \\
0.0315\end{array}$ & $\begin{array}{l}0.0491 \\
0.0846 \\
0.0846 \\
0.0586\end{array}$ & $\begin{array}{l}0.0545 \\
0.1055 \\
0.1055 \\
0.0681\end{array}$ \\
\hline 550 & $\begin{array}{l}\mathrm{R}_{\mathrm{m}} @ 10 \% \text { conv. } \\
\mathrm{R}_{\mathrm{m}} @ 50 \% \text { conv. } \\
\text { Maxdmum Rm } \\
\text { Maxdmum Ro }\end{array}$ & $\begin{array}{l}0.0501 \\
0.0762 \\
0.0760 \\
0.0550\end{array}$ & $\begin{array}{l}0.0979 \\
0.1273 \\
0.1288 \\
0.0998\end{array}$ & $\begin{array}{l}0.1383 \\
0.2132 \\
0.2132 \\
0.1488\end{array}$ & $\begin{array}{l}0.2608 \\
0.3006 \\
0.3176 \\
0.2506\end{array}$ \\
\hline 600 & $\begin{array}{l}\mathrm{R}_{\mathrm{m}} @ 10 \% \text { conv. } \\
\mathrm{R}_{\mathrm{m}} @ 50 \% \text { conv. } \\
\text { Maximum Rm } \\
\text { Maximum Ro }\end{array}$ & $\begin{array}{l}0.1294 \\
0.1621 \\
0.1621 \\
0.1209\end{array}$ & $\begin{array}{l}0.3287 \\
0.3040 \\
0.3494 \\
0.2990\end{array}$ & $\begin{array}{l}0.6950 \\
0.4189 \\
0.7845 \\
0.6671\end{array}$ & $\begin{array}{l}1.5535 \\
0.6120 \\
1.9437 \\
1.5862\end{array}$ \\
\hline 650 & $\begin{array}{l}R_{m} @ 10 \% \text { conv. } \\
R_{m} @ 50 \% \text { conv. } \\
\text { Maxdmum Rm } \\
\text { Maximum Ro }\end{array}$ & $\begin{array}{l}0.2626 \\
0.2818 \\
0.2818 \\
0.2376\end{array}$ & $\begin{array}{l}0.6557 \\
0.4889 \\
0.6601 \\
0.5903\end{array}$ & $\begin{array}{l}1.8167 \\
0.9321 \\
1.9623 \\
1.6959\end{array}$ & $\begin{array}{l}5.7044 \\
1.8923 \\
7.4687 \\
5.6820\end{array}$ \\
\hline 700 & $\begin{array}{l}\mathrm{R}_{\mathrm{m}} @ 10 \% \text { conv. } \\
\mathrm{R}_{\mathrm{m}} @ 50 \% \text { conv. } \\
\text { Maximum Rm } \\
\text { Maximum Ro }\end{array}$ & & $\begin{array}{l}1.6809 \\
1.1148 \\
1.9640 \\
1.6680\end{array}$ & $\begin{array}{l}3.2404 \\
2.0820 \\
4.3696 \\
3.5909\end{array}$ & \\
\hline
\end{tabular}

The most significant feature of the $R_{0}$ vs conversion patterns is the maxdmum they exhibit in the $10-30 \%$ conversion range. As we have shown in our earlier studies, this maximum results from two competing processes: pore growth and pore coalescence. Initially the pores grow resulting in increasing speclfic surface area and increasing rate. When they 
grow enough, however, adjacent pores coalesce driving down the overall surface area and reaction rate.

At low temperatures, there are no significant diffusional limitations and the maximum is observed for conversions in the 30-35\% range. This is clearly seen in Figure 2 that presents the evolution of the normalized $R_{0}$ and $R_{m}$ rates with conversion at $500 \mathrm{C}$. The normalized $R_{0}$ rates agree extremely well for all oxygen concentrations, even though the actual $R_{m}$ rates are quite dufferent. The $R_{0}$ rates were normalized here with respect to their maximum value.

When the reaction rates get higher and diffusional limitations in the micropores get into play, the maxdmum $R_{0}$ is observed at much lower conversion. This is shown in Figure 3 that presents the reactivity curves at $650 \mathrm{C}$ and three oxygen concentrations. All $R_{0}$ vs conversion curves now exhlbit a sharp maximum in the $15-20 \%$ range. Also, a characteristic inflection point develops and becomes more pronounced as the oxygen concentration and consequently the rate of reaction increases.

Figure 4 compares the reactivity patterns obtained at three different temperatures with the same oxygen concentration (10\%). The conversion at which the maxdmum of the $R_{0}$ curve occur decreases as the reaction rate increases (higher temperatures). Also, the characteristic inflection point appears at $550 \mathrm{C}$ for conversions between $35-40 \%$ and it becomes much more pronounced (and shifted to slightly lower conversions) as the temperature increases. The experimental results also show that this shift does not depend strongly on the partial pressure of the oxygen. It may be possible however that the higher flow rates chosen for the $40 \%$ axygen have slightly shifted the the maximum to slightly higher values (by $2-3 \%$ ).

The changes in the reactivity patterns are the results of the appearance of intraparticle diffusional limitations in the char The oxygen concentration inside the particle decreases with increasing distance from the particle surface and, thus, the pores that are closer to the particle exterior react faster than the inner pores whose degree of utilization is limited.

The evolution of the intrinstc reaction rates $R_{m}$ (defined per mass of remaining coal) with conversion. is also of great importance. At low temperatures, (see Figure 2, for example) 


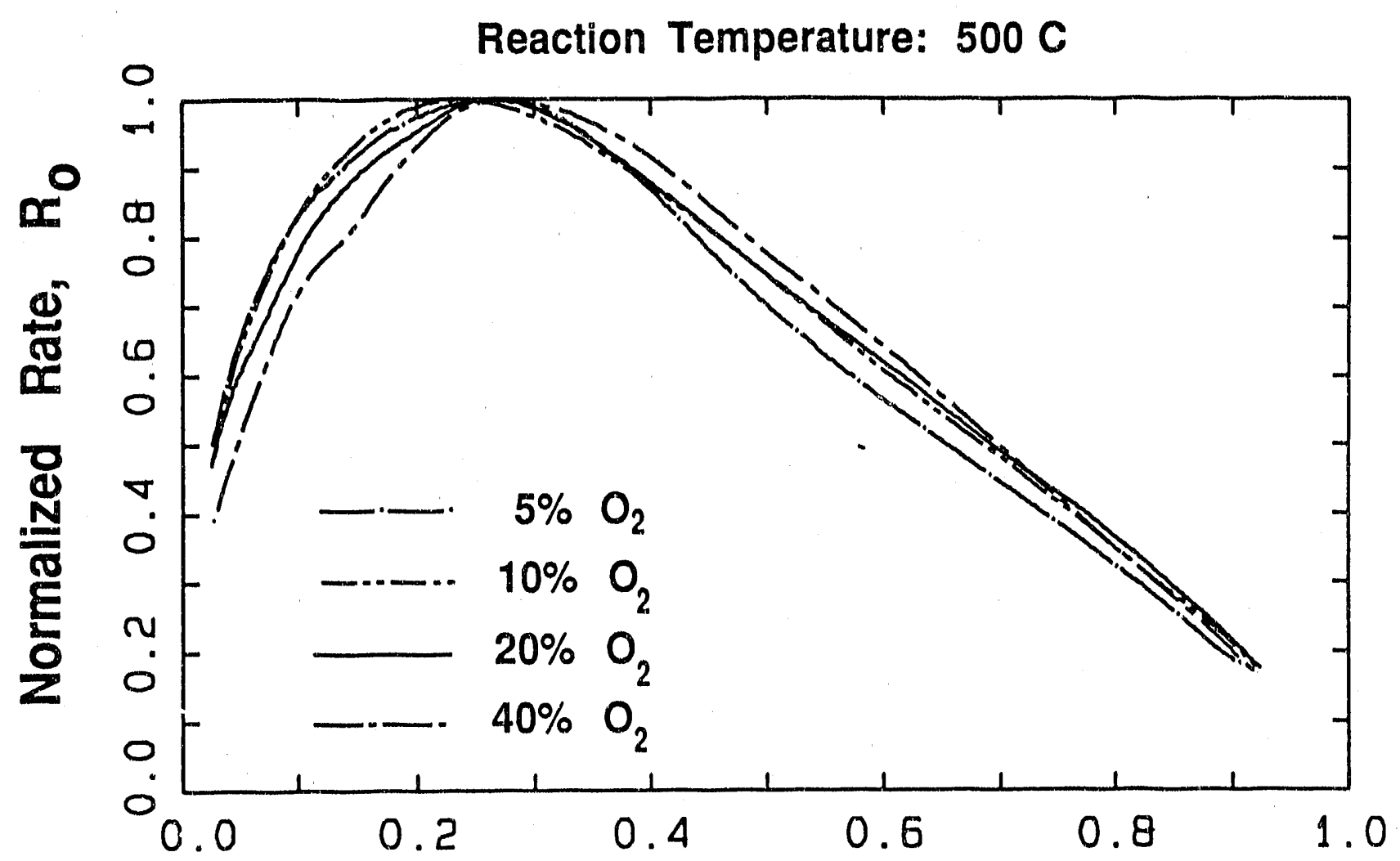

Conversion

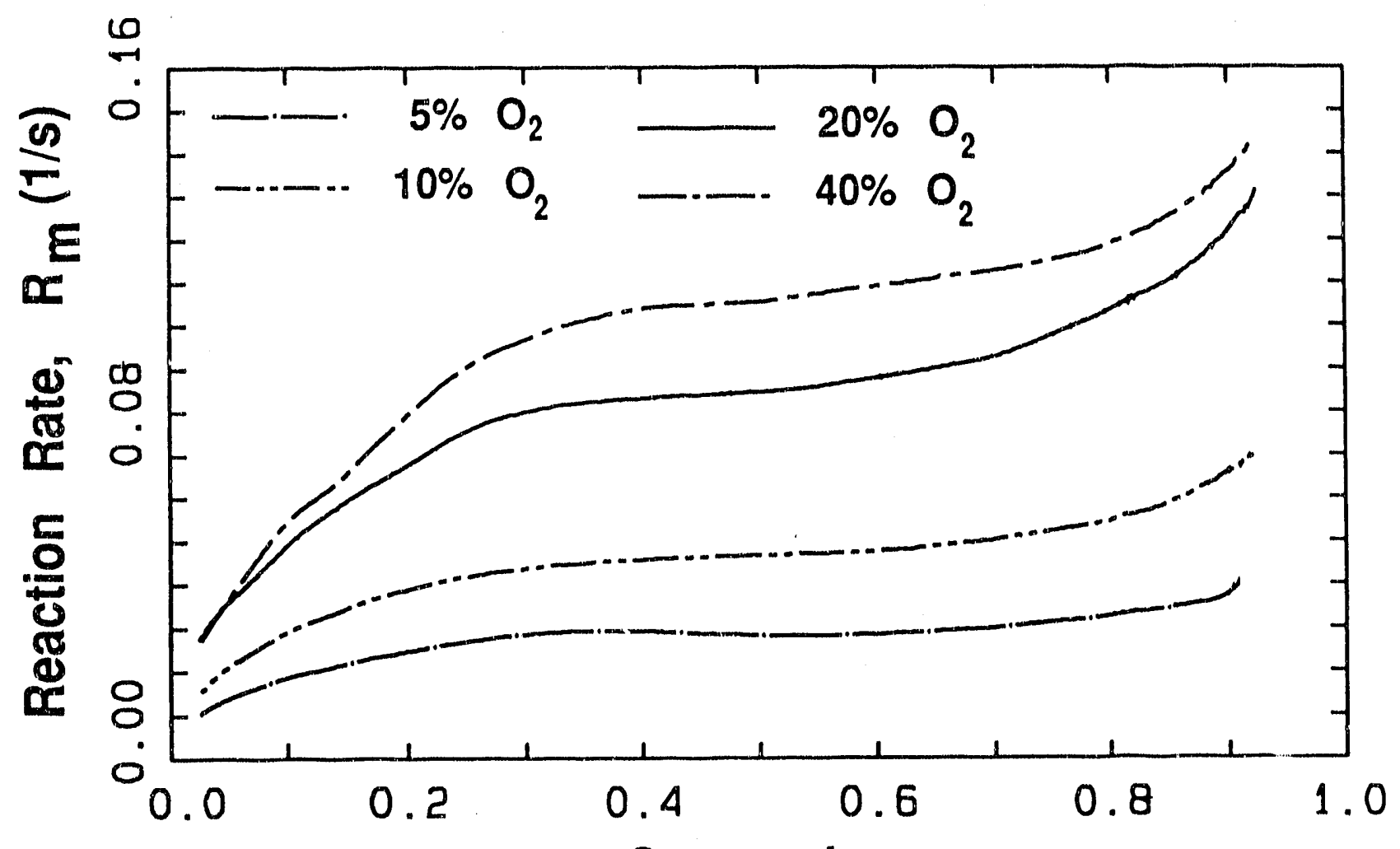

Conversion

Figure 2: Reactivity vs conversion patterns for reaction of a demineralized Illinois $\# 6$ char at $500 \mathrm{C}$ and four axygen coneentrations.

Reaction takes place under ldnetic control at these conditions. 


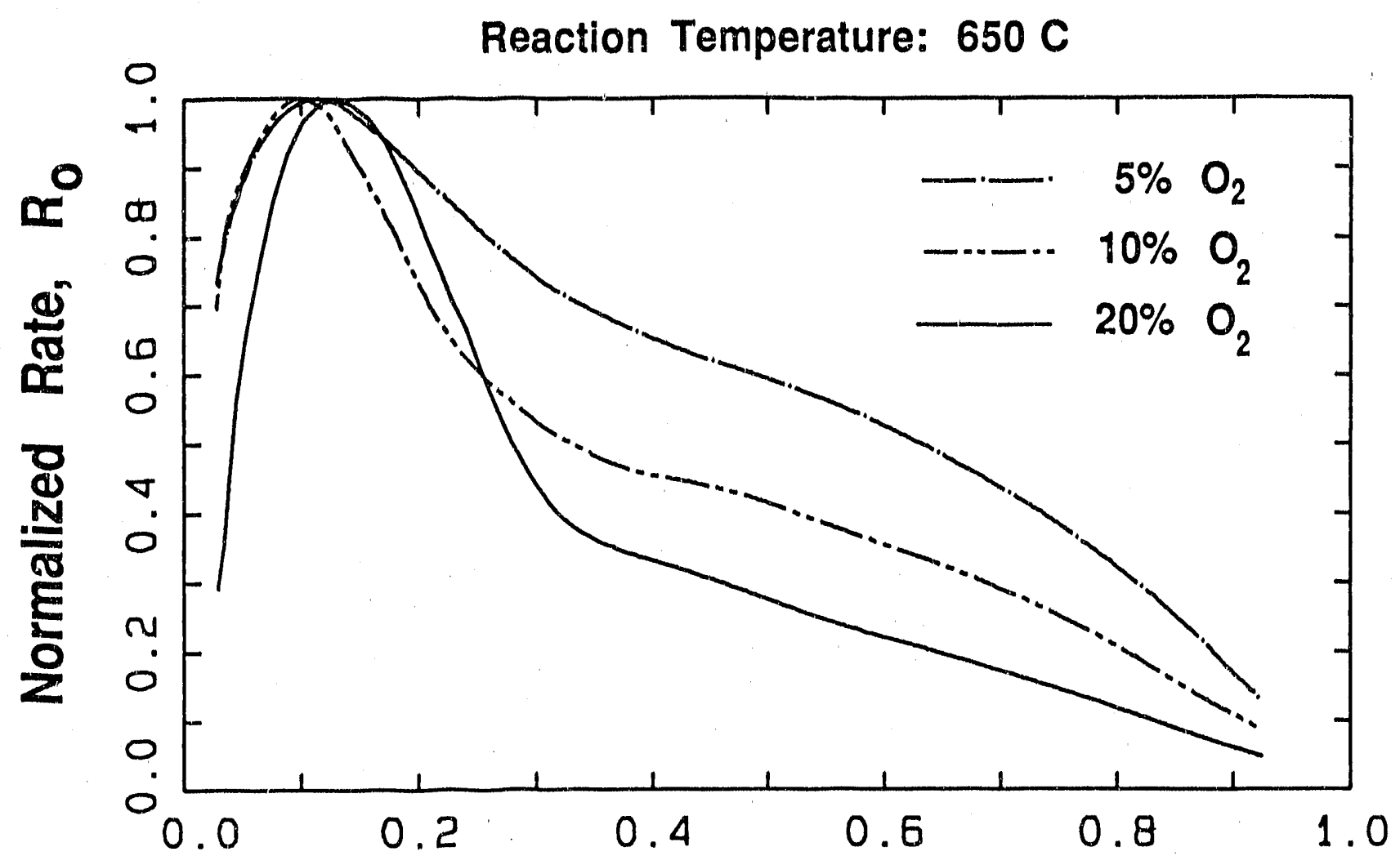

Conversion

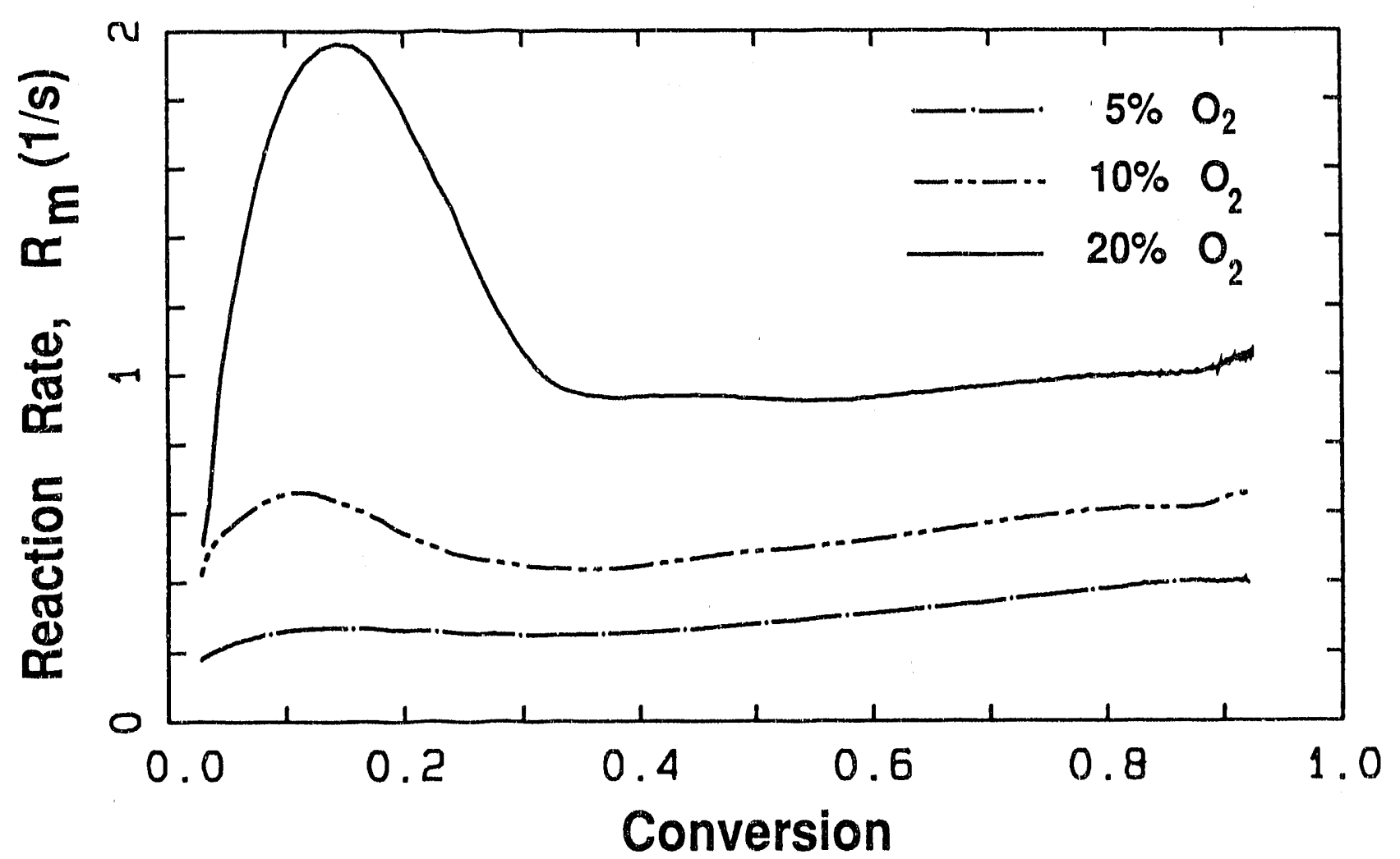

Figure 3: Reactivity vs conversion patterns for reaction of a demineralized Illinois $\# 6$ char at $650 \mathrm{C}$ and three oxygen coneentrations. Intraparticle diffusional limitations are present under these conditions. 

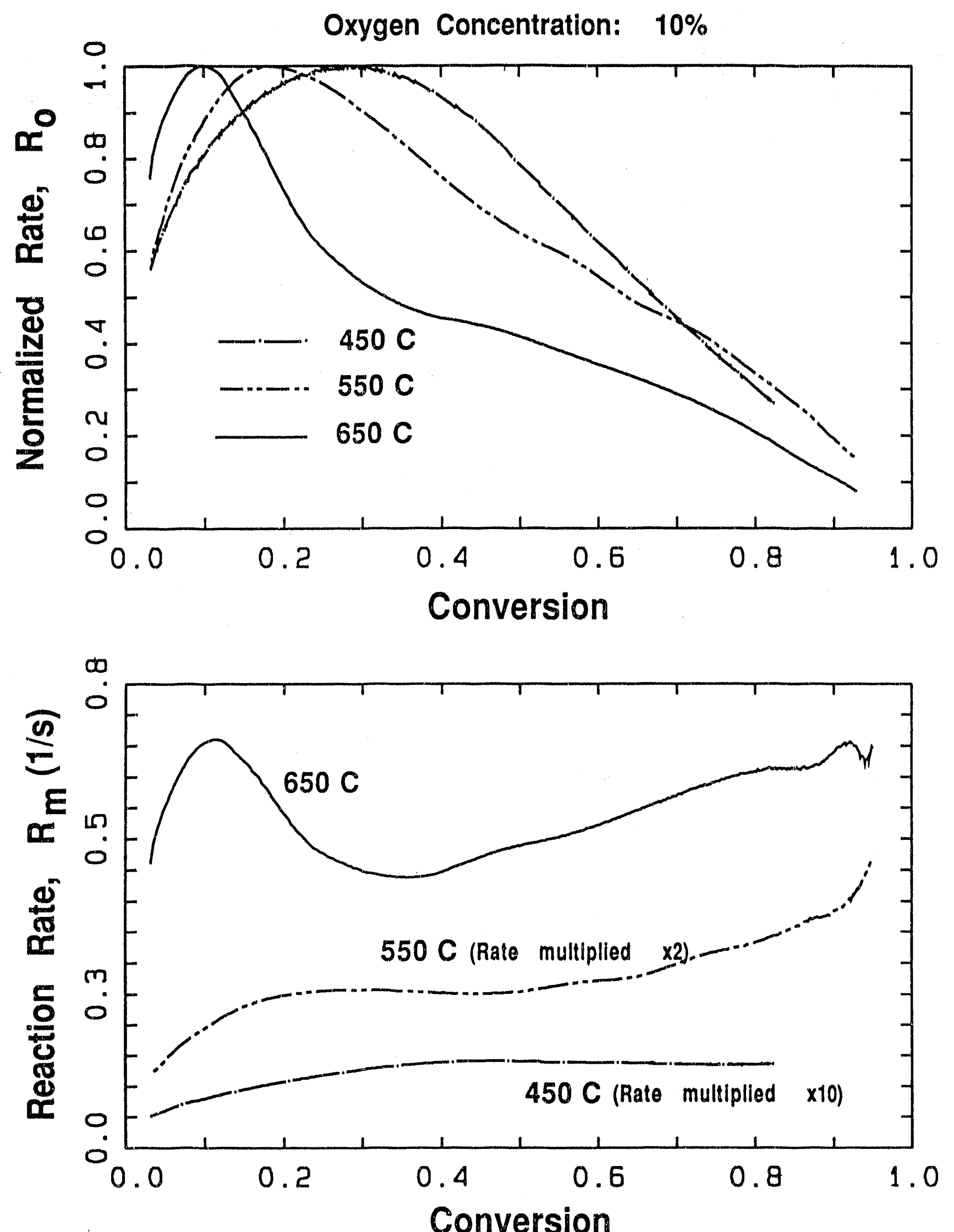

Figure 4: Reactivity vs conversion patterns for reaction of a demineralized Illinois \#6 char at three temperatures 
$R_{\mathrm{m}}$ initially increases reaching a plateau at approximately $25-35 \%$ conversion. Thereafter, it remains constant untll about $80 \%$ conversion, after which it again increases rapidly.

A different behavior is observed at higher temperatures (600-750 C). As shown in Figure 2. $R_{m}$ exhibits a pronounced maxdmum at rather low conversions. The maxdmum is followed by a sharp drop and $R_{m}$ reaches again a plateau at $35-40 \%$ conversion. This xisy mean that even though the pores in an outer shell have reacted, the pores in the core of the particle are still inaccessible to the reactant gas.

At even higher temperatures $(800 \mathrm{C})$, other features appear in the reactivity patterns. As shown in Figure 5, the $\mathrm{Rm}$ reactivity curves do not exhlbit a maxdmum at low conversions. The reaction rate increases monotonically until high conversions (80\%) are achieved.

This is the behavior predicted by our theoretical models when diffusional limitations In the micropores become so severe that they are completely inaccessible to the reactants. Reaction then takes place in the larger pores only. However, the interpretation of data is complicated here by the high converstons obtained before the final reaction temperature is reached (note the arrows on Figure 5).

If we assume a first order reaction with respect to oxygen and divide the reaction rates given by Table 2 by the corresponding partial pressure of oxygen (0.05 to $0.4 \mathrm{~atm})$, an Arrhenius plot can be obtained (see Figure 6). The computed apparent activation energy from this plot behaves like a linear function of the partial pressure of oxygen as silown in Table 3. These results show that the order of reaction changes with increasing temperature and oxygen partial pressure. Thus, char combustion does not follow first-order kinetics, an observation that agrees with experimental data avallable in the literature.

We have developed an empirical correlation that accurately describes our kdnetic data for temperatures as high as $800 \mathrm{C}$. Such correlations (a different one is required for each char) can be used to improve the accuracy of our temperature control algorithms 

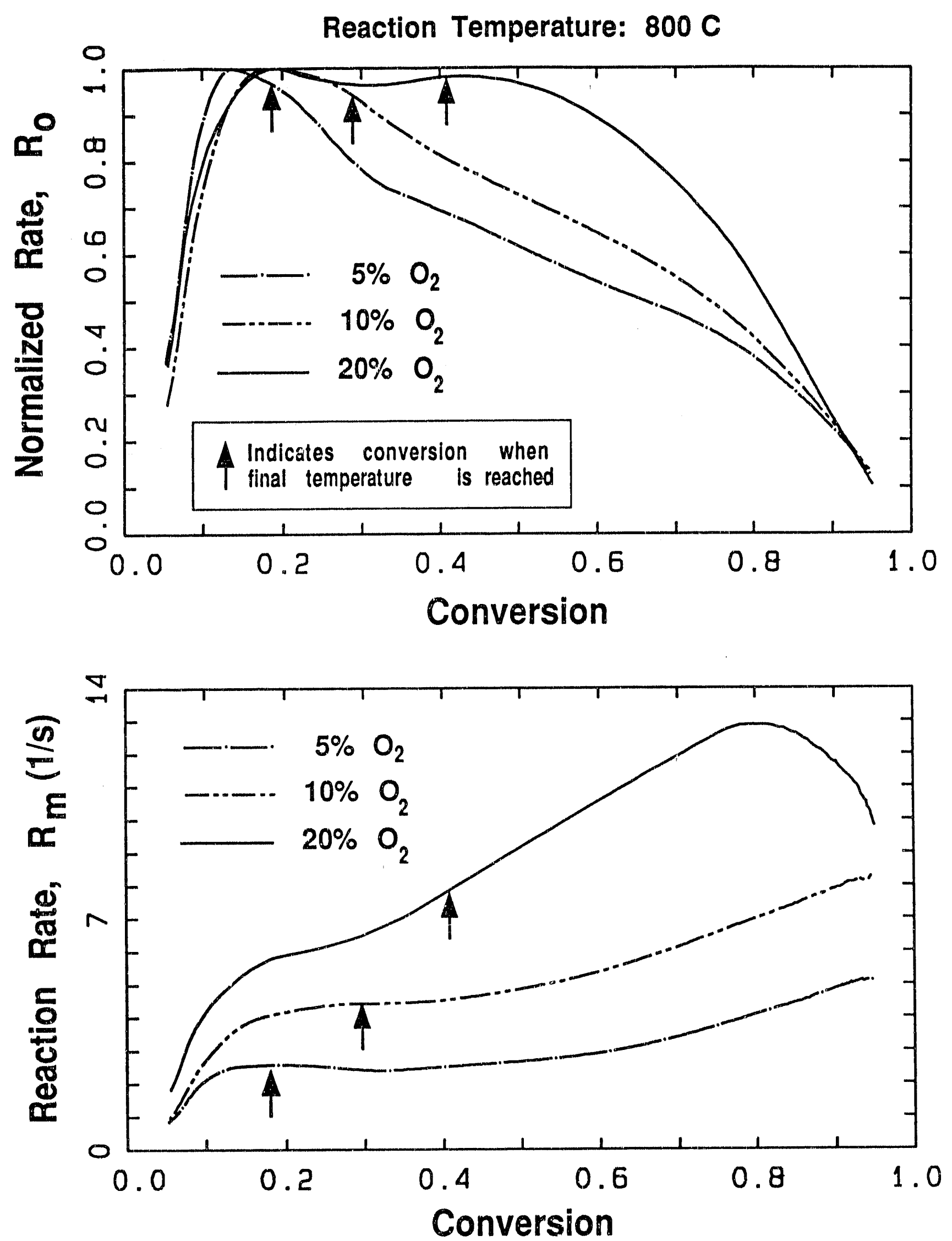

Figure 5: Reacttvity vs conversion patterns for reaction of a demineralized Illinois $\# 6$ char at $800 \mathrm{C}$ and three axygen concentrations. 
TABLE 3

Values of the Apparent Activation Energy for Various Partial Pressures of Oxygen

\begin{tabular}{|c|c|c|c|c|}
\hline OXYGEN CONCENTRATION & $5 \%$ & $10 \%$ & $20 \%$ & $40 \%$ \\
\hline $\mathrm{E}(\mathrm{kcal} / \mathrm{gmol})$ & 30.57 & 35.81 & 40.69 & 49.51 \\
\hline
\end{tabular}

External Mass Transfer Llmitations: When the gasification experiments were performed with a higher total flow rate $(250 \mathrm{sccm}$ instead of the standard $200 \mathrm{sccm}$ ), a slight increase in the reaction rates was observed when the temperature was above $600 \mathrm{C}$. However, the observed differences were small and fell within the range of reproducibility errors. We cannot take them therefore as a clear indication of external mass transfer limitations.

In the next quarter, we plan to continue our studies on char combustion in the regime of intraparticle diffusional limitations. Higher total flow rates will be employed and the TGA will be modifled to improve mixing of gases in the reaction region. Two are the objectives of these Investigations: (a) evaluate the importance of diffusional limitations at temperatures higher than 700-750 $\mathrm{C}$ and (b) minimize the transients observed in the beginning of our high temperature experiments. Our efforts will focus on minimizing the non-uniformities in the oxygen concentrations observed during the early stages of "constant temperature" experiments.

The second focus of our efforts will be the validation of our theoretical models using the obtained experimental data. We have already seen that the theoretical models can predict the trends observed in the experimental data (1.e. the trends in the reactivity vs. conversion patterns for increasing temperatures and decreasing degree of utllization of the smaller pores. 


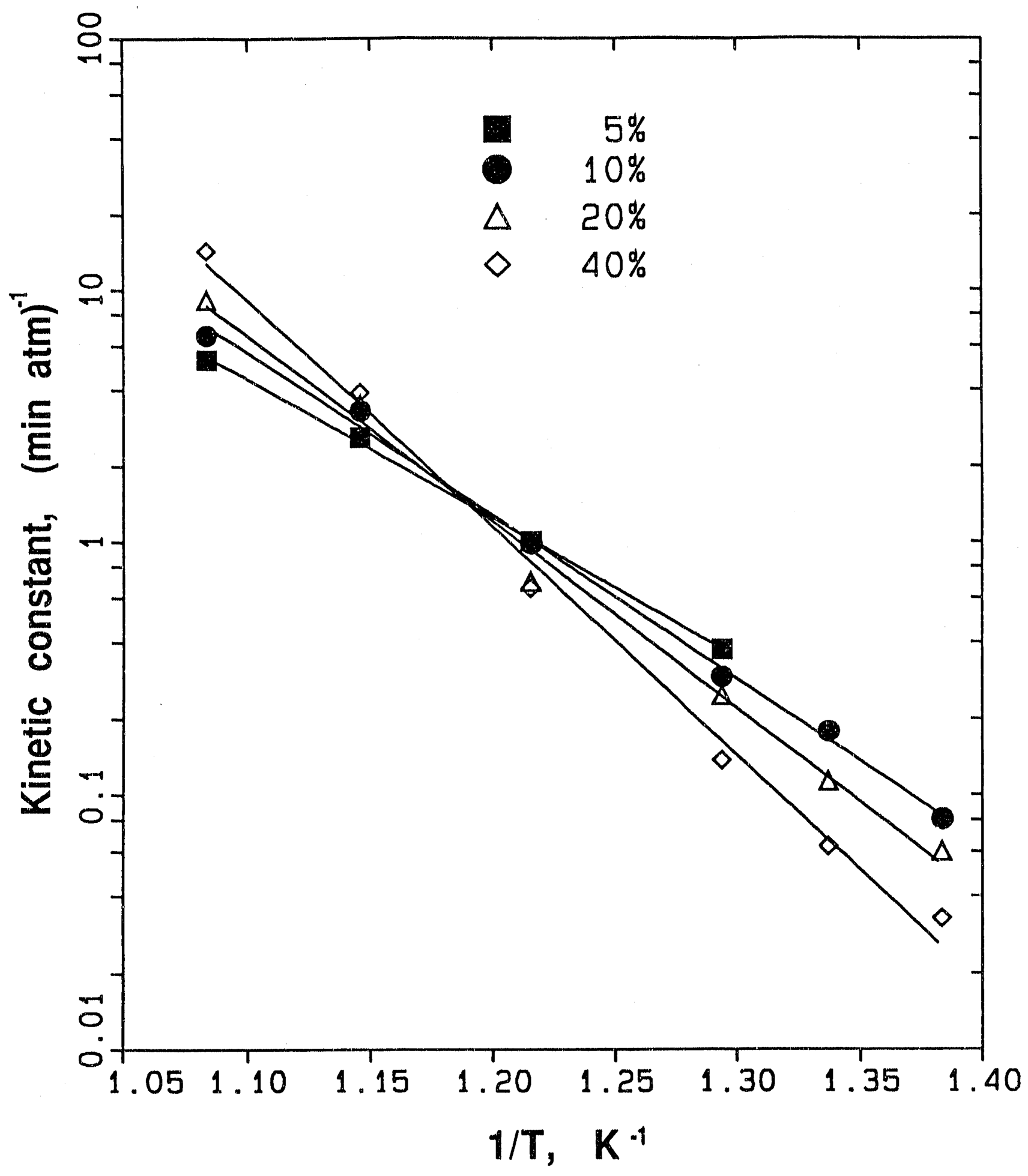

Figure 6: $\quad$ Arrhenlus plots for the reaction of a demineralized Illinols \#6 char at various oxygen concentrations. 

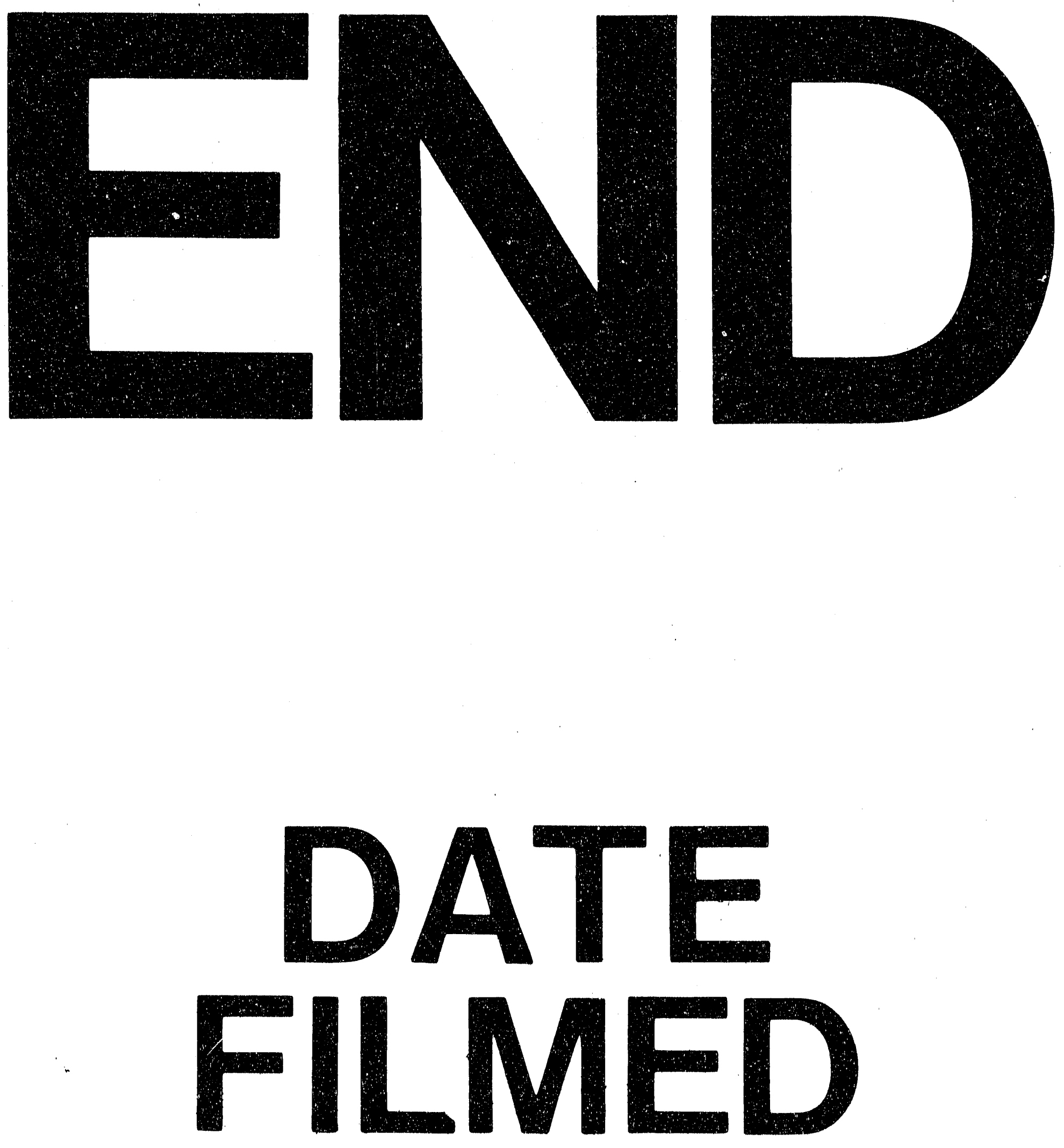

1

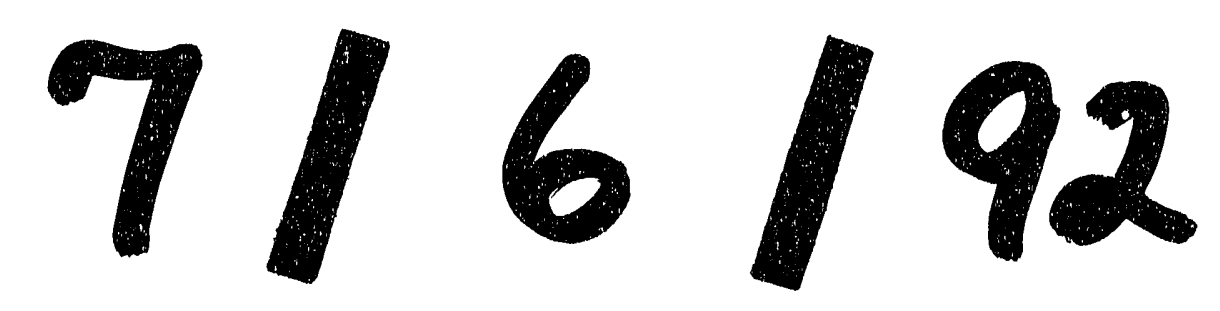


